\title{
Hearing complaints and the audiological profile of the users of an academic health center in the western region of São Paulo
}

\author{
Alessandra Giannella Samelli', Camila Quintiliano de Andrade², Marília Barbieri Pereira³, Carla Gentile Matas4. \\ 1) PhD. Professor in the Department of Physiotherapy, Speech-Language Pathology, \& Audiology, Occupational Therapy. School of Medicine. University of São Paulo. \\ 2) Audiologist. \\ 3) Speech Therapist and Audiologist. Speech Therapist in the Department of Physiotherapy, Communication Science, \& Disorders, Occupational Therapy. School of Medicine \\ University of São Paulo. \\ 4) PhD. Professor in the Department of Physiotherapy, Speech-Language Pathology, \& Audiology, Occupational Therapy. School of Medicine. University of São Paulo. \\ Institution: Department of Physiotherapy, Speech-Language Pathology, \& Audiology, Occupational Therapy. School of Medicine. University of São Paulo. \\ São Paulo / SP - Brazil. \\ Mailing address: Department of Physiotherapy, Speech-Language Pathology, \& Audiology, Occupational Therapy - School of Medicine. University of São Paulo - \\ Profa. Dra. Alessandra Giannella Samelli-Rua Cipotânia, 51 - Cidade Universitária São Paulo-São Paulo/SP - Brazil-Zip code: 05360-160 - E-mail: alesamelli@usp.br \\ Fundação de Amparo à Pesquisa do Estado de São Paulo (Processo nº 2008/09659-7) \\ Article received on May 8, 2012. Article accepted on December 16, 2012
}

\section{SUMMARY}

Introduction: Few population-based studies have quantified hearing levels in Brazil; additional studies on this subject are needed.

Purpose: The purpose of this study was to characterize hearing complaints and the audiological profile of the population served by the Clinical Audiology Service of an Academic Health Center in the western region of São Paulo, Brazil, between 2003 and 2008. An additional aim was to check whether there is a positive association between the signs/symptoms and type of hearing loss.

Methods: This was a retrospective study of the records of 2,145 patients. The health history, tonal and vocal audiometry, and imitanciometry findings were analyzed.

Results: The mean age of the patients was 20.6 years. The majority of the subjects had normal hearing thresholds, and the prevalence of hearing loss was approximately 35\%. As the patient's age increased, the frequency of conductive hearing loss decreased and that of sensorineural hearing loss increased. There was a tendency toward hearing loss worsening with age. Conclusion: Hearing complaints can predict the type of hearing loss; therefore, they should always be valued because they can be used as a form of screening and thus help to determine the diagnostic hypothesis. This could help to reduce the gap between the patient's perception of the complaints and the audiological assessment and thus improve the prognosis.

Keywords: Hearing; Hearing Loss; Prevalence.

\section{INTRODUCTION}

There have been only a few population-based studies quantifying the hearing levels of the population of Brazil: 1 study of Canoas, Rio Grande do Sul (1), 1 study of Juiz de Fora, Minas Gerais (2), and 1 study of Itajaí, Santa Catarina (3). These studies found prevalence rates of disabling hearing loss (an average of $41 \mathrm{~dB}$ or more for adults or $31 \mathrm{~dB}$ or more for children at 500 , $1,000,2,000$, and $4,000 \mathrm{~Hz}$ in the best ear (4)) of $6.8 \%$, $5.2 \%$, and $16.84 \%$ (in children above 4 years of age), respectively.

Studies on the hearing loss in a community are vital at all levels of health care for devising public health measures that suit the needs of the population (5). This type of survey of health conditions has often been performed through population-based inquiries; this method differs from that of demand studies that include only individuals who use specific health equipment (6).
On the other hand, studies based on household inquiries are restricted to individuals' self-reported health conditions and thus cannot use quantitative measures to characterize hearing loss (5).

Although this limitation does not diminish the importance of population-based studies using inquiries, further studies that better characterize hearing problems are also needed to clarify the types of hearing complaints that the inquiries should investigate.

Demand studies can thus complement the gaps left by inquiry studies and help with identification of risk factors, planning of health promotion programs, early diagnosis, habilitation, and rehabilitation $(6,7)$.

Moreover, demand studies can aid the decentralization policy of the Sistema Único de Saúde - SUS (Brazilian national health system), helping the Health Councils to control the fulfillment of its principles and promote people's participation in 
managing their health by focusing on the real health demands of a specific population and supporting decisions that consider the different interests of each segment (users, managers, service providers, and health workers) (8).

Therefore, the objective of this study was to characterize hearing complaints and the audiological profile of the users of an Academic Health Center in the western region of Sao Paulo, Brazil, to determine whether there is a positive association between the signs/symptoms and type of hearing loss.

\section{Methods}

This study was approved by the Ethics Committee for the Analysis of Research Projects of the School of Medicine, University of São Paulo, under approval number $1005 / 08$. It was a retrospective study using the medical records of 2,145 patients who enrolled in the Clinical Audiology Service of an Academic Health Center between 2003 and 2008. All of the patient records from this period included anamnesis (hearing complaints), tonal audiometry (or behavioral hearing assessment), vocal audiometry, and impedance findings.

The evaluations were classified as normal (normal hearing thresholds based on audiometric thresholds for frequencies from 250 to $8,000 \mathrm{~Hz}$ ) or altered (presence of hearing loss) (9). Hearing losses, in turn, were classified by type (conductive, sensorineural, mixed, or isolated) and degree (minimal, from 16 to $25 \mathrm{~dB}$; mild, 26-40 dB; moderate, 41-55 dB; moderately severe, 56-70 dB; severe, 71-90 dB; profound, $>90 \mathrm{~dB}$ ) (10). The type of hearing loss was classified by comparison of the hearing thresholds by air and bone conduction as well as findings concerning tympanometry and the presence or absence of acoustic reflexes.

\section{Statistical Analysis}

The associations between age, sex, and otologic signs and symptoms and hearing loss were evaluated using the Chi-square test. When this test was not appropriate, the likelihood ratio test was used instead. The association between age and the type of hearing loss was assessed using the Kruskal-Wallis test.

The frequencies of conductive and sensorineural hearing loss (in relation to normal hearing) according to age, sex, and otologic signs and symptoms were compared using adjusted multinomial logistic regression models; the type of hearing loss was considered the response variable, and age, sex, or otologic signs and symptoms were considered the explanatory variables.

Hearing loss severity was considered ordinal and scored from 1 to 7 . The associations between severity and sex and between severity and age were assessed using the Mann-Whitney and Kruskal-Wallis tests, respectively. The significance level for hypothesis testing was set at 0.05 .

\section{RESULTS}

1) Characteristics of the sample (sex and age)

The mean age of the sample was 20.6 years $(0-95$ years). There was a significantly higher percentage of males (52.2\%) than of females ( $47.8 \% ; \mathrm{p}=0.03)$. More than $50 \%$ of the population was referred for audiological evaluation by a pediatrician or otolaryngologist.

The age distribution of the sample was as follows: 0 to 5 years, $22.5 \%$; 6 to 11 years, $36.6 \%$; 12 to 17 years, $13.5 \%$; 18 to 30 years, $3.4 \%$; 31 to 50 years, $7.7 \%$; 51 to 65 years, $8.2 \%$; 66 years or older, $8.1 \%$.

2) Audiological profile of the sample: hearing loss type

This analysis considered only the ears for which complete audiometry results were available (right ear $=$ 1,812 and left ear $=1,809$ ). The greatest number of the ears had normal hearing thresholds, followed in turn by ears with sensorineural hearing loss and those with conductive hearing loss (Table 1).

Both the percentage of normal results and the percentage of ears with conductive hearing loss tended to decrease with increasing age, whereas the prevalence of sensorineural hearing loss increased with age. The distributions of the types of hearing loss differed significantly among the age groups $(\mathrm{p}<0.001$ for both the right ear and left ears) (Table 1).

The association between age and the type of hearing loss was also assessed by comparing the ages of the individuals with different types of loss (Table 2). Individuals with sensorineural hearing loss were, on average, older than individuals with other types of hearing loss.

3) Characteristics of the sample in terms of the most prevalent otologic signs and symptoms according to age

The most prevalent otologic symptom was pain (56.9\%), followed by infection (35.2\%), otitis (33.6\%), and 
Table I. Distribution (\%) of the subjects in each age group according to the type of hearing loss and ear.

\begin{tabular}{|c|c|c|c|c|c|c|c|c|c|c|}
\hline \multirow{3}{*}{ Age Group } & \multicolumn{10}{|c|}{ Type of hearing loss } \\
\hline & \multicolumn{2}{|c|}{ Normal } & \multicolumn{2}{|c|}{$\mathrm{SHL}$} & \multicolumn{2}{|c|}{ CHL } & \multicolumn{2}{|c|}{$\| \mathrm{L}$} & \multicolumn{2}{|c|}{$\mathrm{MHL}$} \\
\hline & $\mathrm{RE}$ & LE & RE & LE & RE & LE & $\mathrm{RE}$ & LE & RE & LE \\
\hline $0-5$ & 82.4 & 85.8 & 0.3 & 0.3 & 15.8 & 13.0 & 0.9 & 0.6 & 0.6 & 0.3 \\
\hline $6-11$ & 80.8 & 82.9 & I.I & I.I & 16.9 & 14.2 & 1.3 & 1.4 & 0.0 & 0.5 \\
\hline $12-17$ & 78.9 & 78.9 & 5.1 & 6.5 & 10.2 & 11.3 & 4.7 & 2.9 & 1.1 & 0.4 \\
\hline $18-30$ & 55.1 & 62.3 & 24.6 & 26.1 & 4.5 & 7.2 & 2.9 & 2.9 & 2.9 & 1.4 \\
\hline $31-50$ & 45.3 & 41.0 & 32.3 & 36.0 & 9.3 & 9.3 & 7.5 & 7.5 & 5.6 & 6.2 \\
\hline $5 \mid-65$ & 29.1 & 25.6 & 44.2 & 49.4 & 4.7 & 5.2 & 14.0 & 12.8 & 8.1 & 7.0 \\
\hline$\leq 66$ & 5.2 & 5.2 & 80.9 & 82.1 & 1.2 & 1.2 & 4.6 & 4.0 & 8.1 & 7.5 \\
\hline Total & 64.5 & 65.4 & 16.9 & 18.2 & 12.3 & 10.7 & 3.9 & 3.4 & 2.4 & 2.3 \\
\hline $\mathrm{N}$ & 1,169 & 1,183 & 307 & 329 & 222 & 194 & 70 & 62 & 44 & 41 \\
\hline
\end{tabular}

Legend: RE, $\mathrm{p}<0.001$; LE, $\mathrm{p}<0.001$. RE, right ear; LE, left ear; NHL, sensorineural hearing loss; CHL, conductive hearing loss; IHL, isolated hearing loss (1 frequency); MHL, mixed hearing loss.

Table 2. Age (in years) of the patients with each category of hearing loss in each ear.

\begin{tabular}{lcccccccccccc}
\hline Type of $H L$ & \multicolumn{3}{c}{$\mathrm{N}$} & \multicolumn{2}{c}{ Mean } & \multicolumn{2}{c}{ Standarddeviation } & \multicolumn{2}{c}{ Minimum } & \multicolumn{2}{c}{ Median } & \multicolumn{2}{c}{ Maximum } \\
& RE & LE & RE & $L E$ & RE & LE & RE & LE & RE & LE & RE & LE \\
\hline Normal & 1,169 & 1,183 & 13.5 & 13.0 & 13.4 & 128 & 0 & 0 & 10 & 10 & 73 & 75 \\
$\mathrm{NHL}$ & 307 & 329 & 58.8 & 58.0 & 21.3 & 21.3 & 0 & 0 & 64 & 62 & 95 & 95 \\
$\mathrm{CHL}$ & 222 & 194 & 13.5 & 14.5 & 14.1 & 15.0 & 2 & 2 & 10 & 10 & 70 & 70 \\
$\| H L$ & 70 & 62 & 40.0 & 40.3 & 23.1 & 22.6 & 4 & 3 & 47 & 46.5 & 87 & 87 \\
$\mathrm{MHL}$ & 44 & 41 & 53.1 & 52.6 & 21.7 & 22.8 & 5 & 5 & 55 & 54 & 88 & 88 \\
\hline Total & 1,812 & 1,809 & 23.1 & 23.2 & 23.8 & 23.8 & 0 & 0 & 11 & 11 & 95 & 95 \\
\hline
\end{tabular}

Legend: This analysis considered only individuals for whom complete tonal audiometry results were available (RE $=1,812$, $\mathrm{LE}=1$,809). HL, hearing loss; RE, right ear; LE, left ear; NHL, sensorineural hearing loss; CHL, conductive hearing loss; IHL, isolated hearing loss (1 frequency); MHL, mixed hearing loss.

Table 3. Distribution (\%) of subjects in each age group according to their reported otologic symptoms (pain, dizziness, suppuration, infection, otitis, ear fullness, itching, and occupational noise exposure).

\begin{tabular}{lccccccccc}
\hline Age group & Pain & \multicolumn{2}{c}{ Dizziness Suppuration } & Tinnitus & Infection & Otitis & Earfullness & Itching & Occupational noise \\
\hline $0-5$ & 63.3 & 1.0 & 25.1 & 2.3 & 43.6 & 44.4 & 7.1 & 28.6 & 0.0 \\
$6-11$ & 62.1 & 4.1 & 24.9 & 7.9 & 43.6 & 41.7 & 11.1 & 23.8 & 0.0 \\
$12-17$ & 65.2 & 11.7 & 25.9 & 17.2 & 34.8 & 27.9 & 22.1 & 23.4 & 0.0 \\
$\mid 8-30$ & 58.9 & 43.8 & 23.3 & 56.2 & 28.8 & 35.6 & 34.2 & 46.6 & 12.3 \\
$31-50$ & 50.9 & 52.1 & 18.2 & 72.1 & 23.0 & 27.3 & 40.0 & 57.6 & 36.4 \\
$51-65$ & 33.7 & 61.7 & 8.6 & 79.4 & 12.0 & 9.7 & 36.6 & 50.3 & 41.1 \\
$\leq 66$ & 29.9 & 58.0 & 11.5 & 70.1 & 11.5 & 5.7 & 27.6 & 56.9 & 20.7 \\
\hline Total & 56.9 & 18.6 & 22.1 & 25.4 & 35.2 & 33.6 & 18.1 & 33.1 & 8.4 \\
\hline$N$ & 1,220 & 398 & 474 & 544 & 754 & 721 & 388 & 709 & 180 \\
\hline
\end{tabular}

itching (33.1\%). Infection, suppuration, and otitis occurred most frequently in younger individuals, whereas tinnitus, itching, ear fullness, and dizziness occurred more often in individuals aged 18 years or older. Occupational noise was reported most frequently in individuals aged 30 to 65 years (Table 3).

Dizziness, tinnitus, ear fullness, and occupational noise were all uncommon among individuals under 18 years of age. In contrast, infection and suppuration were more frequent in these younger subjects.

4) Associations of age, sex, and otologic signs and symptoms with the type of hearing loss

As the prevalence rates of various otologic signs and symptoms differed between subjects aged from zero to 17 years and those 18 or more years of age, the associations 
Table 4. Distribution (\%) of subjects of each age group and sex according to the type of hearing loss in each ear.

\begin{tabular}{|c|c|c|c|c|c|c|c|c|c|c|c|}
\hline \multirow{3}{*}{ Age group (years) } & \multirow{3}{*}{ Sex } & \multicolumn{8}{|c|}{ Type of hearing loss } & \multirow{2}{*}{\multicolumn{2}{|c|}{$\mathrm{MHL}$}} \\
\hline & & \multicolumn{2}{|c|}{ Normal } & \multicolumn{2}{|c|}{$\mathrm{NHL}$} & \multicolumn{2}{|c|}{$\mathrm{CHL}$} & \multicolumn{2}{|c|}{$\Vdash \amalg$} & & \\
\hline & & RE & LE & RE & LE & RE & LE & RE & $\mathrm{LE}$ & RE & LE \\
\hline \multirow[t]{4}{*}{$0-17$} & Male & 79.5 & 80.5 & 2.1 & 2.6 & 16.2 & 14.9 & 1.7 & 1.6 & 0.4 & 0.4 \\
\hline & Female & 82.4 & 85.7 & 1.3 & 1.5 & 13.7 & 10.9 & 2.3 & 1.5 & 0.4 & 0.4 \\
\hline & $\%$ & 80.8 & 82.7 & 1.8 & 2.1 & |5.| & 13.2 & 1.9 & 1.5 & 0.4 & 0.4 \\
\hline & $N$ & 999 & $\mid, 02$ | & 22 & 26 & 187 & 163 & 24 & 19 & 5 & 5 \\
\hline \multirow[t]{4}{*}{$\leq 18$} & Male & 17.7 & 19.9 & 60.2 & 62.4 & 7.5 & 4.9 & 5.8 & 6.2 & 8.8 & 6.6 \\
\hline & Female & 37.2 & 33.5 & 42.7 & 46.4 & 5.2 & 5.7 & 9.5 & 8.3 & 5.4 & 6.0 \\
\hline & $\%$ & 29.6 & 28.2 & 49.6 & 52.7 & 6.1 & 5.4 & 8.0 & 7.5 & 6.8 & 6.3 \\
\hline & $N$ & 170 & 162 & 285 & 303 & 35 & 31 & 46 & 43 & 39 & 36 \\
\hline
\end{tabular}

Legend: RE, $0-17$ years-old: $p=0.522 ; 18$ or more years old: $\mathrm{p}<0.001 ; \mathrm{LE}, 0-17$ years old: $\mathrm{p}=0.179 ; 18$ or more years old: $\mathrm{p}=0.002$. RE, right ear; LE, left ear; NHL, sensorineural hearing loss; CHL, conductive hearing loss; IHL, isolated hearing loss (1 frequency); MHL, mixed hearing loss.

Table 5. Distribution (\%) of the subjects in each age group according to the severity of the hearing loss in the right and leftears.

\begin{tabular}{|c|c|c|c|c|c|c|c|c|c|c|c|c|}
\hline \multicolumn{13}{|l|}{ Severity } \\
\hline \multirow{2}{*}{ Age group } & \multicolumn{2}{|c|}{ Minimal } & \multicolumn{2}{|c|}{ Mild } & \multicolumn{2}{|c|}{ Moderate } & \multicolumn{2}{|c|}{ Mod-severe } & \multicolumn{2}{|c|}{ Severe } & \multicolumn{2}{|c|}{ Profound } \\
\hline & RE & LE & RE & LE & RE & LE & $\mathrm{RE}$ & LE & $\mathrm{RE}$ & LE & $\mathrm{RE}$ & LE \\
\hline $0-5$ & 27.1 & 40.5 & 60.4 & 52.4 & 12.5 & 7.1 & 0.0 & 0.0 & 0.0 & 0.0 & 0.0 & 0.0 \\
\hline $6-11$ & 44.9 & 45.0 & 42.9 & 43.8 & 6.1 & 3.8 & 0.0 & 1.3 & 3.1 & 2.5 & 3.1 & 3.8 \\
\hline $12-17$ & 29.3 & 33.3 & 34.1 & 31.0 & 7.3 & 4.8 & 9.8 & 9.5 & 2.4 & 0.0 & 17.1 & 21.4 \\
\hline $18-30$ & 8.0 & 9.5 & 12.0 & 23.8 & 12.0 & 9.5 & 16.0 & 4.8 & 16.0 & 19.0 & 36.0 & 33.3 \\
\hline $31-50$ & 4.9 & 7.5 & 39.3 & 28.4 & 16.4 & 26.9 & 14.8 & 13.4 & 8.2 & 9.0 & 16.4 & 14.9 \\
\hline $5 \mid-65$ & 4.1 & 3.8 & 46.6 & 41.8 & 17.8 & 27.8 & 12.3 & 7.6 & 5.5 & 5.1 & 13.7 & 13.9 \\
\hline$\leq 66$ & 0.0 & 0.8 & 53.2 & 49.2 & 29.8 & 31.0 & 12.1 & 12.7 & 3.2 & 3.2 & 1.6 & 3.2 \\
\hline Total & 16.4 & 17.1 & 45.1 & 41.4 & 16.6 & 19.5 & 8.7 & 8.1 & 4.5 & 4.4 & 8.7 & 9.6 \\
\hline $\mathrm{N}$ & 77 & 78 & 212 & 189 & 78 & 89 & 41 & 37 & 21 & 20 & 41 & 44 \\
\hline
\end{tabular}

Legend: RE, right ear; LE, left ear; Mod-severe, moderately severe.

of otologic symptoms with the type of hearing loss were evaluated separately in the 2 groups.

The p-values in the legend of Table 4 indicate that hearing loss was not associated with sex in the zero- to 17year-old age group. In the group aged 18 or more years, the frequency of conductive hearing loss in the right ear was lower in females ( $p=0.003)$, while that in the left ear did not differ between the sexes $(p=0.388)$. Sensorineural hearing loss tended to be more frequent in men than in women $(p<0.001$ in both ears).

5) Audiological profile of the sample: degree of hearing loss

This part of the analysis considered only individuals who had altered audiometric results and hearing loss severity ranging from minimal to profound. Mild hearing loss was the most prevalent condition. There was also a trend toward hearing loss worsening with age (Table 5).

\section{Discussion}

The present study is limited in that the data come from a population served in an academic health center; therefore, this is not a population-based study. However, given the lack of studies in the area ( 7 ), the findings of this study may serve to help identify the complaints and hearing problems that are more prevalent in this region of São Paulo, which could contribute to the improvement of identification tools and future data management. It can also contribute to determining the prevalence of hearing impairment in a population of a greater area as well as to the implementation of large-scale screenings that can reach more people at more affordable costs to the government.

The mean age of the patients was 20.6 years, with a minimum age of zero and a maximum of 95 years. This reflects the great variety of the patients seen in the Clinical 
Audiology Service, CSE, as this service receives patients referred by the Pediatric and Adult and Elderly Health Services as outpatients referred from various other services of the health system. As most of the referrals are from Pediatric services, over half of the individuals were between zero and 11 years of age.

The percentage of males in the sample was significantly higher than that of females. This may be related to the higher incidence of hearing loss in men reported in the literature (6), which could lead to a greater number of referrals of males.

The percentage of normal audiometric results tended to decrease with increasing age, whereas the percentage of those indicating sensorineural hearing loss increased and the percentage of those indicating conductive hearing loss decreased with age. Furthermore, individuals with sensorineural hearing loss were on average older than those with other types of hearing loss. The subjects with normal hearing or conductive hearing loss had a lower mean age; these findings are possibly related to otitis media, the incidence and prevalence of which are higher in pre-school and school-aged children and decrease over time $(11,12)$. In turn, individuals with mixed, sensorineural, and isolated hearing loss were older than average, which could be due to presbycusis, exposure to ototoxic agents, and occupational noise, among other risk factors (6). This relationship between increasing age and increasing prevalence of hearing loss has also been observed in several other studies (1,2,5-7).

The present study found that the signs and symptoms (hearing complaints) reported in the anamnesis of infection, suppuration, and otitis media were more prevalent in younger individuals. These findings could be related to middle ear problems and upper respiratory infections, which are more common in younger individuals (13). They may also be associated with the higher incidence of conductive hearing loss in younger individuals.

The otologic symptoms of tinnitus, itching, ear fullness, and dizziness were reported with higher frequency by individuals aged 18 or more years. One previous study (14) reported that vertigo and tinnitus were among the symptoms most frequently reported by patients with sensorineural hearing loss, the more prevalent type of hearing loss in adults in this sample.

The high reported history of exposure to occupational noise in patients between 30 and 65 years of age is attributable to the fact that most individuals in this age group perform some sort of professional activity, which often involves noise. These data could also be related to the higher incidence of sensorineural hearing loss in older individuals (especially males) observed in this sample, as noise exposure is a risk factor for this type of hearing loss $(5,6)$.

The age distribution of the data related to otologic signs and symptoms is consistent with that of the types of hearing loss, suggesting that patients' complaints should be valued because they may indicate the type of hearing disorder present (7).

It should be emphasized that the younger subjects had higher prevalence rates of normal hearing and conductive hearing loss, which was consistent with infection, suppuration, and otitis media being the most prevalent signs and symptoms in these patients.

In turn, older subjects showed higher prevalence rates of sensorineural, isolated, and mixed hearing loss, which was consistent with tinnitus, itching, and dizziness being the most prevalent otologic signs in these patients.

The comparison of individuals' audiological assessment results by sex found no significant difference for individuals aged zero to 17 years, similar to the findings of another study (15). For subjects aged over 18 years, sensorineural hearing loss tended to occur more frequently in men than in women, which has also been observed in other studies (1,2,5,6). Hypertension, smoking, and noise exposure were found to contribute to the worsening of hearing loss with age and had more severe effects in male patients (16); this would explain the higher prevalence of hearing loss in men, especially those over 18 years of age.

The hearing loss was mild in most cases, which can be partly explained by the fact that the mean age of the studied population was relatively low. Our findings showed a trend toward the severity of hearing loss worsening with advancing age, as previously reported (1).

In summary, our study revealed that hearing complaints (signs and symptoms reported by the patient) correlated positively with the type of hearing loss and can thus be predictive. Therefore, hearing complaints should be valued and can be used as a screening tool to help the clinician to determine the diagnosis. This could contribute to reducing the gap between the patient's perception of the complaint and the audiological diagnosis, which might improve the prognosis and, possibly, decrease the demand for audiological evaluation.

\section{CONCLUSION}

We found that the most common otologic signs and symptoms and types of hearing loss agreed for each age 
group, emphasizing that patients' complaints should always be valued and can help to determine the audiological diagnosis more precisely and to improve the prognosis.

Sensorineural hearing loss was more prevalent among older individuals, whereas conductive hearing loss was more prevalent among the younger age group. The severity of the hearing loss tended to worsen with advancing age.

\section{REFERENCES}

1. Béria JU, Raymann BCW, Gigante LP, Figueiredo ACL, Jotz G, Roithman R, et al. Hearing impairment and socioeconomic factors: a population-based survey of an urban locality in southern Brazil. Rev Panam Salud Publica. 2007;21(6):381-7.

2. Baraky LR, Bento RF, Raposo NR, Tibiriçá SH, Ribeiro LC, Barone MM, Vasconcelos NB. Disabling hearing loss prevalence in Juiz de Fora, Brazil. Braz J Otorhinolaryngol. 2012;78(4):52-8.

3. Balen SA, Debiasi TF, Pagnossim DF, Broca VS, Roggia SM, Gondim LM. Caracterização da audição de crianças em um estudo de base populacional no município de Itajaí / SC. Arq Int Otorrinolaringol. 2009;13(4):372-80.

4. World Health Organization (WHO). Future programme developments for prevention of deafness and hearing impairment. Report of first informal

Consultation, Geneva, 23-24 January 1997 [Internet]. [cited 2009 Sept.]. Available from: http://whqlibdoc.who.int/hq/ 1997/WHO_PDH_97.3.pdf.

5. Cruz MS, Oliveira LR, Carandina L, Lima MCP, CésarChester LG, Barros MBA et al. Prevalência de deficiência auditiva referida e causas atribuídas: um estudo de base populacional. Cad Saúde Pública. 2009;25(5):1123-31.

6. Castro SS, Galvão CCL, Carandina L, Barros MBA, Alves MCGP, Goldbaum M. Deficiência visual, auditiva e física: prevalência e fatores associados em estudo de base populacional. Cad Saúde Pública. 2008;24(8):1773-82.

7. Marini ALS, Halpern R, Aerts D. Sensibilidade, especificidade e valor preditivo da queixa auditiva. Rev Saúde Pública. 2005;39(6):982-4.

8. Brasil. Ministério da Saúde. Conselho Nacional de Saúde. Diretrizes nacionais para o processo de educação permanente no controle social do SUS / Ministério da Saúde, Conselho Nacional de Saúde. Brasília: Editora do Ministério da Saúde; 2006.

9. Russo ICP, Pereira LD, Carvallo RMM, Anastásio ART. Encaminhamentos sobre a classificação do grau de perda auditiva em nossa realidade. Rev Soc Bras Fonoaudiol. 2009;14(2):287-8

10. Northern JL, Downs MP. Hearing in children. Baltimore: Lippincott Williams and Wilkins; 1991.

11. Smith AW. WHO activities for prevention of deafness and hearing impairment in children. Scand Audiol Suppl. 2001;(53):93-100.

12. Vidal SR, Silva EV, Oliveira MG, Siqueira AM, Felisberto E, Samico I, et al. Avaliação da aplicação da estratégia da Atenção Integrada às Doenças Prevalentes da Infância por Agentes Comunitários de Saúde. Rev Bras Saúde Matern Infant. 2003;3(2):205-13.

13.Genov IR, Roxo Júnior P. Otite média recorrente na infância. Medicina, Ribeirão Preto. 2001;34:297-300.

14. Jurca APK, Pinheiro FCC, Martins KC, Herrera LF, Colleone LM, Saes SO. Estudo do perfil audiológico de pacientes com idade a cima de 60 anos. Salusvita, Bauru. 2002;21(1):51-8.

15. Lee IWCC, Brasileiro HMS, Boldorini PR, Rapoport A, Novo NF. Perfil Epidemiológico das Deficiências Auditivas no Interior de São Paulo - Estudo de 234 casos. Rev. Bras. de Cirurgia de Cabeça e Pescoço. 2004;33(2):89-92. 